\title{
BIODIVERSIDAD Y TAXONOMÍA DE LA FLORA DESÉRTICA DEL SUR DE PERÚ: FAMILIA NOLANACEAE
}

\author{
BIODIVERSITY AND TAXONOMY OF SOUTHERN PERU DESERTIC FLORA: \\ FAMILY NOLANACEAE
}

\author{
Rosario Zegarra Zegarra ${ }^{1}$
}

\begin{abstract}
RESUMEN
A pesar de las condiciones climáticas y edáficas desfavorables, el ecosistema desértico del sur de Perú y norte de Chile presenta una diversidad vegetal con más de 200 especies fanerogámicas. Esta flora desértica sudamericana es particularmente rara y muy interesante desde el el punto de vista taxonómico, ecológico y fisiogenético. Como resultado de una intensiva y continua evolución bajo condiciones muy desfavorables, esta vegetación desértica se ha adaptado a este ecosistema árido e hiperárido, mostrando conspicuamente gran tolerancia a muchos estreses abióticos, tales como sequía, salinidad, toxicidad de boro y otros estreses. La semilla botánica seca esparcida al suelo por muchas especies desérticas, después de un corto periodo vegetativo y floración temprana, permanece viable en la arena caliente por más de diez años. La presencia ocasional de densas y bajas neblinas durante el invierno humedece suficientemente los suelos arenosos de las colinas y planicies costaneras permitiendo la germinación, desarrollo y reproducción rápida de estas plantas. En algunas localidades costeras los ciclos de vegetación de lomas pueden ser cada año, cada cinco años, cada diez años y cada veinte años o más en una misteriosa combinación de la presencia de condiciones climáticas favorables y formación de lomas costeras en vegetación efímera.

En esta publicación se describen once especies del género Nolana (Nolanaceae), las cuales son mayormente endémicas de la formación de lomas del desierto sur peruano.
\end{abstract}

Palabras clave: Nolanaceae, vegetación costera árida, biodiversidad.

\section{ABSTRACT}

Although the southern Peru and northern Chile coastal desert formations represent one of the driest deserts of the world they allow the development and reproduction of more than 200 phanerogamic plant species. This South American desertic flora is particularly rare and very interesting under taxonomic, ecological, and fisiogenetic point of view.

As a result of an intensive and continuous evolution under the very hard growing conditions, this special desertic vegetation have become adapted and tolerant to the most common abiotic stress of the arid and hiperarid agroecological zones, conspicuously displaying tolerance to drought, salinity, boron toxicity and others stress. Dry botanical seeds shet to the ground after very short growing period and early flowering by several desertic species surprisinly remain viable in the hot sandy desert for more than five, ten and even twenty years. The occasional occurrence of a favorable winter weather conditions with a very dense and low fog dampens the sandy soils of coastal plains and hills allowing the germination, development and fast reproduction of this particular vegetation. In some places the cycles on Loma vegetation can be every year, or every five, ten, twenty or more years in a mysterious timing combinations of favorable climatic conditions and loma formations.

In the paper, the writer describes eleven species of Nolana (Nolanaceae) which are mainly endemic of the Loma formation of southern Peru desert.

Keywords: Nolanaceae, arid coastal vegetation, biodiversity.

1 Facultad de Ciencias Agrícolas, Universidad Nacional Jorge Basadre Grohmann, Tacna, Perú, email; rzegarra@ unjbg.edu.pe

Fecha de Recepción: 13 Abril 2006

Fecha de Aceptación: 19 Mayo 2006 


\section{INTRODUCCIÓN}

La costa peruana es en su mayoría árida e hiperárida; involucra áreas desérticas con escasa vegetación xerófita, de igual manera extensas zonas hiperáridas sin ninguna vegetación (Ferreyra, 1953). El desierto de la costa del Pacífico en Sudamérica empieza en los $5^{\circ}$ de latitud sur en el departamento de Piura en el norte de Perú y se extiende hasta los $27^{\circ}$ de latitud sur al norte de Chile (Rundel et al. 1991). El territorio peruano desértico abarca casi $2.300 \mathrm{~km}$ de longitud, y una altitud que puede llegar hasta los 1.000 m.s.n.m. con anchura de $20-100 \mathrm{~km}$ (Ferreyra, 1960).

$\mathrm{La}$ aridez y el hiperxerofitismo van aumentando gradualmente a medida que se avanza hacia el sur y es en el desierto de Atacama donde alcanza su mayor expresión, el cual es considerado el más seco del mundo. A pesar de las condiciones muy desfavorables para el crecimiento de las plantas, el desierto es el recinto fascinador de una diversidad de plantas y su estudio y conocimiento integral constituyen aspectos trascendentales para el manejo, explotación y conservación de los recursos vegetales de los territorios áridos (Zegarra, 2005, Chávez, 2002).

El extremo meridional del país presenta extensos territorios desérticos a lo largo y ancho de la franja costanera, desierto que no es homogéneo en toda su extensión, sino que tiene una fisiografía compleja, la misma que presenta diferentes tipos de vegetación xerófita. Las lomas constituyen una rara formación vegetal compuesta mayormente por plantas efímeras, las cuales crecen en las zonas donde las densas y bajas nieblas invernales son interceptadas por las laderas de pequeñas elevaciones que miran a la costa. El número total de especies de plantas desérticas presentes en las lomas de la costa desértica de Perú es de 557, aunque cada loma individualmente suele tener menos de 100 (Brako y Zarucchi, 1993).

Dentro de las formaciones de lomas, uno de los elementos más conspicuos lo constituyen las especies de las familias Solanaceae y Nolanaceae (Zegarra, 2005), grupo de plantas de mayor distribución y variación de la flora costanera presente en casi todas las formaciones lomales (Rundel $e t$ al., 1991). A la fecha se han reportado cerca de 40 especies de Nolanas en Perú (de las cuales 33 son endémicas); 39 en Chile, al menos tres distribuidas en ambos países, y una en las islas Galápagos (Brako y Zarucchi, 1993, Puppo, 2005).
El género Nolana fue descrito por Linneo hace más de 250 años. Son hierbas o pequeños arbustos en su mayoría de hojas suculentas, tienen flores actinomorfas, pentámeras y muy vistosas, que van desde el blanco hasta varios tonos de azul, y su fruto es de tipo esquizocarpo, el cual da origen a varias nueces (Puppo, 2005). Su nombre se debe al latin "nola" que significa campanilla, que alude a la forma mayormente campanulada e infundibuliforme de sus flores. Aunque para muchos las Nolanas siempre han conformado una familia aparte (Nolanaceae), actualmente existe la tendencia de algunos taxónomos en incorporar al género Nolana dentro de la familia Solanaceae. Uno de los grupos taxonómicos estudiados de la vegetación desértica de gran importancia botánica y fisiogenética es la familia Nolanaceae, que agrupa 11 especies, la cual es analizada y descrita en la presente publicación.

\section{MATERIALES Y MÉTODOS}

Para la realización del presente trabajo ha sido necesaria la utilización de materiales de diversa índole, obvios de mencionar, ya que son utilizados en todo trabajo de investigación ecológica y botánica. Sin embargo, cabe mencionar que el material más importante de trabajo constituye las colecciones de especímenes vegetales colectados a lo largo y ancho del desierto costanero sur peruano. Durante los viajes de investigación botánica se ha tratado, en todos los casos, de ubicarse, en áreas bien representativas y características, y no en zonas de transición que pudieran inducir a confusiones. Se realizaron los siguientes pasos:

a) Observaciones de la vegetación,

b) Toma de datos ecológicos,

c) Toma de muestras de suelos para su análisis físico y químico,

d) Toma de vistas geográficas,

e) Herborización,

f) Identificación taxonómica,

g) Bioensayos en laboratorio e invernadero.

Una vez preparado el material en estudio, se procedió a la investigación, haciendo uso de obras especializadas, utilización de claves botánicas e identificación del material.

Algunos ejemplares fueron identificados en:

1) Herbario del Museo de Historia Natural "Javier Prado" de Lima y 
2) Missouri Botanical Garden, U.S.A.

Para la ubicación taxonómica de las especies y su descripción se ha utilizado el sistema Taxonómico de Cronquist.

\section{FAMILIA NOLANACEAE}

La familia Nolanaceae representa un grupo taxonómico importante y representativo en la formación de lomas, y forma parte integrante del Dominio Fitogeográfico Costero, Provincia de las Lomas (Ferreyra, 1957). Dicha formación se encuentra desde el centro costero de Chile hasta el norte de Perú. Desde que fue publicado el trabajo de I. M. Johnston (1929), diversos botánicos y colectores han explorado la costa peruana, propiciando un mejor conocimiento actual de su flora. Sin embargo, las investigaciones más profundas e integrales del género Nolana en Perú fueron realizadas por el eminente científico botánico Dr. Ramón Ferreyra, profesor principal y ex Director del Museo de Historia Natural de la Universidad Nacional Mayor de San Marcos de Lima, Perú.

Diversos autores han descrito varias entidades nuevas, procedentes de los departamentos de Ica, Arequipa, Tacna y Moquegua (Ferreyra, 1961). Es de suponer la existencia de especies desconocidas en los lugares de difícil acceso, como la zona comprendida entre la Bahía de la Independencia y el Río Grande, departamento de Ica y en los flancos occidentales de los Andes del Sur. La mayor parte de las Nolanas tiene un hábito herbáceo; los arbustos en su mayor parte proceden de la costa septentrional de Chile. En Perú, N. lycioides y $N$. confinis son arbustos bajos y quedan restringidos principalmente a las lomas del extremo sur de Perú (Nakazawa-Dillon, 1999).

Casi todas las especies anuales poseen raíz pivotante simple más o menos filiforme, solamente en $N$. laxa es ramificada y ligeramente semileñosa (Ferreyra, 1961). En otras como N. arenícola, la raíz principal presenta numerosas raicillas de disposición fasciculada; $N$. spathulata posee una ramificación desde el cuello. Todas las Nolanas anuales tienen tallo erguido. En $N$. amplexicaulis, el tallo es, además, fusiforme y poco ramificado; mientras que $N$. spathulata, $N$. ivaniana, $N$. laxa, $N$. arenicola y $N$. latipes son muy ramificadas desde la base. Por el contrario N. scaposa es conspicuamente acaule. Se caracteriza por su tallo fistuloso y sus ramas superiores dicotómicas $N$. weberbaueri. Las especies perennes se distinguen por su ramificación decumbente, solamente $N$. adansoni y $N$. lycioides, poseen tallo erguido, leñoso y arboriforme (Ferreyra, 1961; Pefaur et al., 1981).

Según el Dr. Ramón Ferreyra (1961), la posición de las hojas en la mayoría de las especies es alterna, pocas son de disposición fasciculada ( $N$. scaposa, $N$. pilosa y $N$. pallida). Por excepción son arrosetadas o semirrosetadas en $N$. inflata. Pueden ser cortas o largamente pecioladas, pocas son sésiles y algunas entidades muestran un limbo amplexicaule como $N$. minor y $N$. amplexicaulis. La forma del limbo es variable, puede ser espatulada, lineal, lanceolada u oblaceolada; estas son las formas más comunes, pero $N$. amplexicaulis se caracteriza por sus hojas reniformes, siendo cordiformes en $N$. adansoni, y $N$. spathulata. El limbo es casi siempre extendido destacándose $N$. plicata, por su margen fuertemente revoluto. El ápice es predominantemente obtuso, raras veces acuminado ( $N$. aticoana y $N$. spengularioides). Por la consistencia suculenta de sus limbos destacan $N$. pallidula y $N$. adansoni (Ferreyra 1961; Nakasawa-Dillon, 1999).

Todas las Nolanas peruanas poseen flores solitarias y axilares. El escapo es muy conspicuo y alcanza hasta $35 \mathrm{~cm}$ en $N$. scaposa. El cáliz es generalmente acampanado, siendo fusiforme en $N$. spathulata y N. tovariana, plegado (N. plicata, $N$. humifusa), o globoso ( $N$. inflata). Los lóbulos del cáliz son 5 ascendentes, algunas especies tienen cáliz bilobulado (N. minor, $N$. thinophila, $N$. tomentella) o trilobulado (N. willeana). El ápice de los lóbulos puede ser agudo, acuminado u obtuso. La corola es infundibuliforme, raras veces tubular ( $N$. thinophila). El color predominante es violáceo, siendo morado únicamente en $N$. inflata. $\mathrm{El}$ andróceo consta de cinco estambres desiguales, dos son mayores, excepto $N$. confinis, que tiene tres estambres mayores y dos menores. Los filamentos se encuentran unidos al tubo corolino a 1/2, 1/3 o $2 / 3$ de su longitud. El material examinado denota un fruto esquizocárpico formado por un número variable de núculas adheridas al receptáculo. Estas pueden ser de 2 hasta 24 (Ferreyra 1961, NakasawaDillon 1999).

En Perú, el género Nolana se distribuye principalmente en la costa, desde el nivel del mar hasta los 900 metros de altitud. Otras habitan en las islas como N. insularis, de la Isla San Gallán, frente a Pisco y N. humifusa en San Lorenzo, frente al 
Callao (Ferreyra, 1961). Son frecuentes los endemismos como $N$. confinis, que viven en los arenales y tablazos alejados del mar (Tacna); las halófitas que están restringidas a las playas marítimas $(N$. adansoni, $N$. thinophila). Sobre suelos cubiertos de cenizas volcánicas del sur (Depto. Arequipa) habita $N$. volcánica. Aparentemente la especie de mayor distribución geográfica es $N$. humifusa, se la encuentra a lo largo de la costa del centro y norte y traspasa los contrafuertes andinos hasta Pallasca y Churín, Departamentos de Ancash y Lima, respectivamente (Ferreira, 1961; Zegarra, 2005).

Dentro de las especies fanerogámicas desérticas y herbáceas de Perú, las once especies de Nolana que se describen en esta publicación constituyen mayormente plantas muy atractivas y ornamentales del desierto, mostrando una extraordinaria adaptación al calor y sequía. Gracias al apoyo científico y valiosa bibliografía del Dr. Ramón Ferreyra y colaboradores, se ha logrado identificar un total de once especies del género Nolana para el desierto sur peruano.

\section{Nolana spathulata $R$. y P.}

Planta anual; tallo de $10-26 \mathrm{~cm}$ de alto, erguido, hirsuta la parte basal glabrescente, ramoso, las ramas de 5-12 cm de largo por 1-4 $\mathrm{mm}$ de diámetro, hirsuto-glandulosas; hojas numerosas, cordiformes o espatulado-reniformes, hirsuto-glandulosas, de $11-40 \mathrm{~mm}$ de largo por $8-38 \mathrm{~mm}$ de ancho, de margen entero, el ápice obtuso: pecíolo de 6-25 $\mathrm{mm}$ de longitud, ligeramente alado, hirsuto-glanduloso; pedicelo de 14-30 mm de largo, hirsuto-glanduloso; cáliz de 13-15 mm de largo por 4-7 $\mathrm{mm}$ de diámetro hirsuto-glanduloso afuera, el tubo fusiforme, ligeramente 5-costado; los lóbulos ascendentes, más o menos espatulados, agudos, de 3,2-6,0 mm de largo por 2,5-6,0 $\mathrm{mm}$ de ancho; corola infundibuliforme, azulada, de $22-28 \mathrm{~mm}$ de largo por $16-18 \mathrm{~mm}$ de ancho en la parte superior, inconspicuamente lobulada, el tubo corto, velloso adentro; estambres desiguales, unidos al tubo más o menos la mitad de su longitud, 2-mayores de 16-17 mm de largo, 3-menores de 12-13 mm de largo; estilo de 11-12 $\mathrm{mm}$ de longitud; núculas 5, uniseriadas, desiguales, reniformes, negruzcas, de 4,2-8,0 $\mathrm{mm}$ de largo por 3-6 mm de ancho; receptáculo ginobásico de 3,5-4,0 $\mathrm{mm}$ de diámetro. Figura 1.

Distribución: Ocupa una vasta extensión en las lomas costaneras de los departamentos de Ica, Arequipa y Tacna, entre los 0-500 metros de altitud.

La presente entidad de caracteriza por su hábito hirsuto-glanduloso, la base del tallo más o menos glabrescente; las hojas cordiformes o espatuladoreniformes, los lóbulos del cáliz conspicuamente espatulados.

\section{Nolana pearcei Johnston}

Hierba anual, erguida de $20-30 \mathrm{~cm}$ de alto, ramosa, las ramas dispuestas en la parte superior,

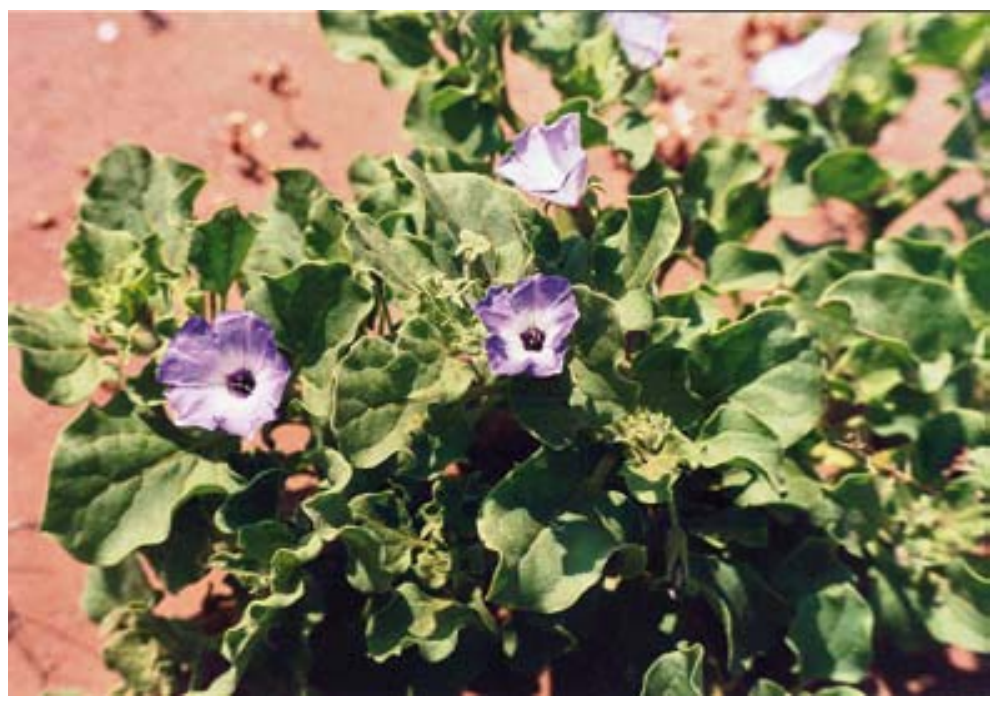

Figura 1. Nolana spathulata, de flores blanco-violáceas en las colinas arenosas de las lomas de Sama-Locumba. 


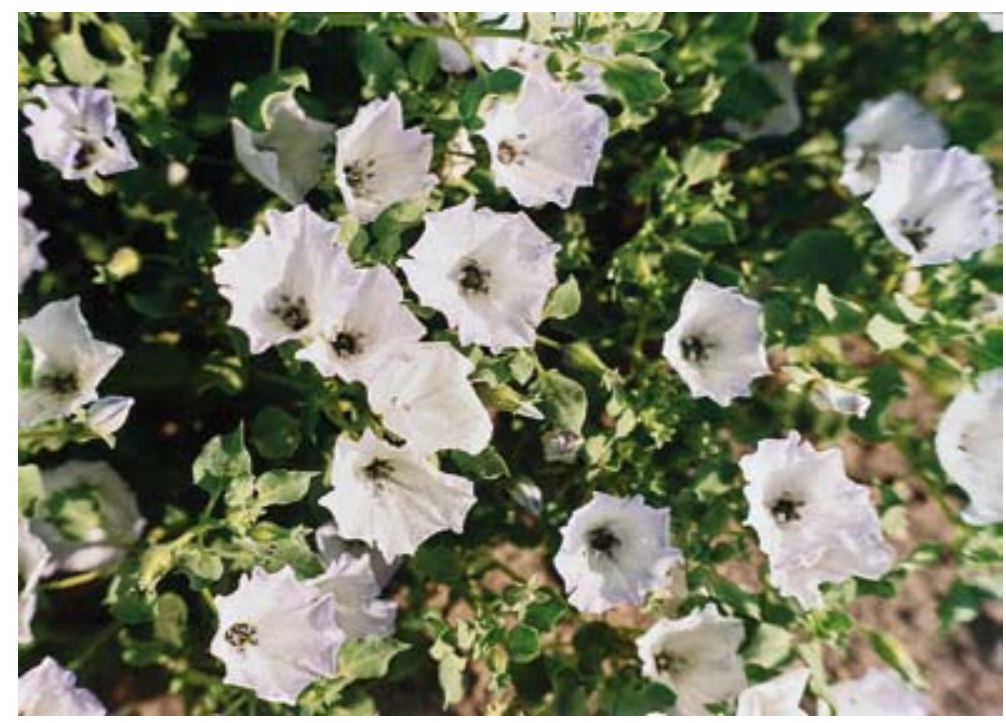

Figura 2. Nolana pearcei, de flores blancas, colinas arenosas de las lomas de Ilo, Moquegua.

inconspicuamente velloso-glandulosas; hojas elípticas o angostamente, de 10-20 $\mathrm{mm}$ de largo por 3-6 mm de ancho, el margen revoluto, el ápice agudo; pecíolo de 6-10 mm de largo; pedicelo hasta $1 \mathrm{~mm}$ de largo; cáliz de 6-8 mm de largo, el tubo cupulliforme, de 2-3 mm de diámetro, los lóbulos, de 1,5-2,5 mm de largo, lineales, desiguales; corola violácea, infudibuliforme, de 20-25 mm de largo, puberula afuera, el tubo brevemente piloso adentro, hasta 1,3 mm de diámetro, los lóbulos ascendentes, de 10-15 mm de diámetro; estambres desiguales, lineales, de 6-8 mm de longitud, glabros; núculas desconocidas. Figura 4.

Distribución: costa sur del Perú, Moquegua, Tacna, Arequipa.

\section{Nolana pallidula Johnston}

Planta desde anual hasta perenne, decumbente, glabrescente, de 10-15 cm de alto; tallo suculento, fistuloso, ramoso, las ramas de 3-6 mm de diámetro, entrenudos de 1-6 cm de largo; hojas espatuladas o angostamente oblanceoladas, suculentas, de 15$40 \mathrm{~mm}$ de largo por 2-6 $\mathrm{mm}$ de ancho, finamente papilosas, el ápice agudo, algunas veces obtuso, la base largamente atenuada; pedicelo de $2-8 \mathrm{~mm}$ de longitud; cáliz turbinado, carnoso, de 18-25 mm de largo por 5-7 mm de diámetro, más o menos bífido, 5-costado, tubo corto, 5-lobulado, los lóbulos ascendentes, de 6-10 mm de largo por 1,0-2,5 $\mathrm{mm}$ de ancho en su base; corola infundibuliforme, violácea, de 20-30 $\mathrm{mm}$ de largo por 18-22 $\mathrm{mm}$ de ancho en la parte superior, 5-lobulada, los lóbulos obtusos, desiguales, tubo corto velloso adentro; estambres desiguales, de $16-18 \mathrm{~mm}$ de longitud, unidos al tubo 1/3 de su longitud estilo de 18-20 mm de largo; núculas (10-12) 5-mayores de 3,5-5,5 $\mathrm{mm}$ de largo por 2-4 $\mathrm{mm}$ de ancho, las menores de 1,5-2,5 mm de largo por 1-2 $\mathrm{mm}$ de ancho, reniformes, negruzcas, brillantes. Figura 3.

Distribución: habita únicamente en las lomas costaneras del extremo meridional de Perú, entre 500-1.000 metros de altitud.

4. Nolana lycioides Johnston, I. M. Johnston

Planta anual o sufruticosa, erguida, arboriforme; raíz más o menos pivotante, de $11-18 \mathrm{~cm}$ de largo por 6-7 $\mathrm{mm}$ de espesor, simple, poco ramificada; tallo erguido, de $16-50 \mathrm{~cm}$ de alto, ramoso las ramas ascendentes, gráciles, más o menos divaricadas, hirsuto-glandulosas; hojas lineales, dispuestas en fascículos alternos, gradualmente más apretados hacia el ápice, sésiles, de 5-9 mm de largo por 0,5$0,9 \mathrm{~mm}$ de ancho, ápice obtuso, la base ligeramente atenuada, semisuculenta, glanduloso-pubescente; pedicelo de 2,4-4,0 mm de longitud, hirsuto-glanduloso, ascendente; cáliz acampanado, de 4,2-5,0 mm de largo por 2,4-2,6 mm de diámetro, hirsutoglanduloso afuera, los pelos glandulosos hasta 1 $\mathrm{mm}$ de largo, el tubo de 1,4-2,0 mm de largo, los lóbulos 5, de 2,8- 3,0 mm de largo por 1,0-1,2 mm 


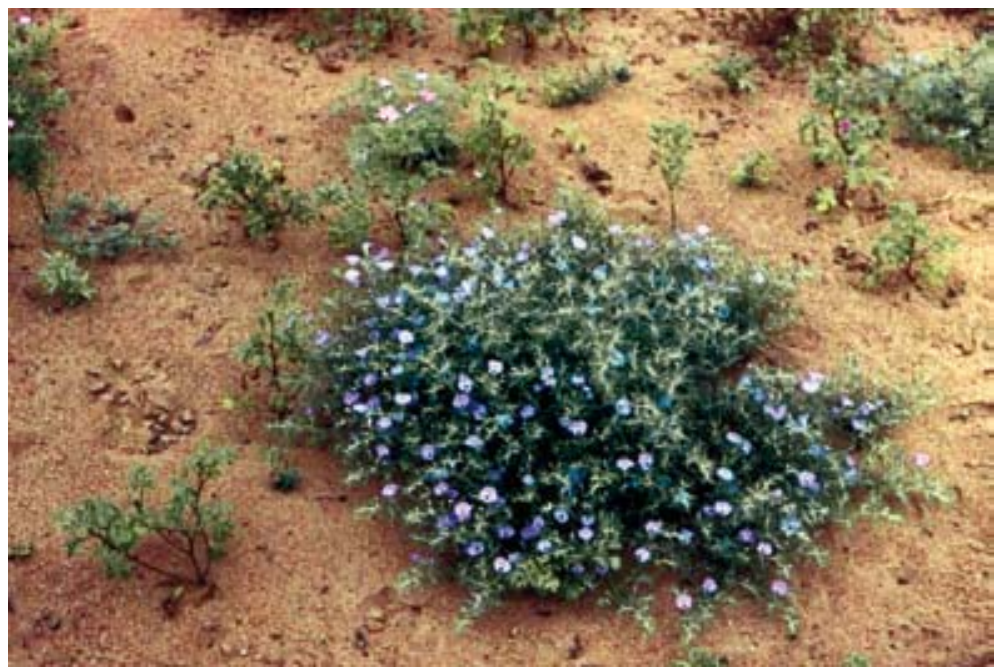

Figura 3. Nolana pallidula, llanuras arenosas de Sama-Locumba.

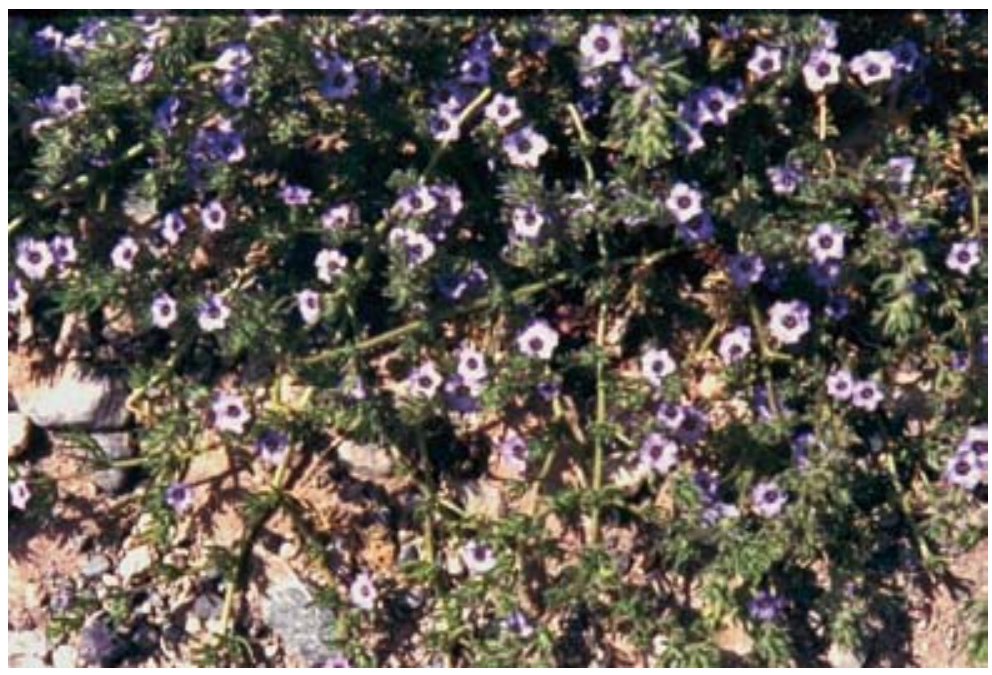

Figura 4. Nolana lycioides, de flores celestes y hojas filiformes en las lomas de SamaLocumba.

de ancho en su base acuminados, ascendentes, pubescentes adentro y afuera; corola infundibuliforme, azul-celeste, de 13-22 mm de largo por 9-12 mm de ancho en la parte superior, 5-lobulada, los lóbulos obtusos, desiguales, el tubo pulcramente hirsuto afuera, velloso adentro; estambres desiguales, 2-mayores de 10-11 mm de largo unidos al tubo 1/2 de su longitud 3-menores de 8,0-8,5 mm de largo, unidos al tubo 1/3 de su longitud; estilo de 9-10 mm de longitud; núculas 5-9, uniseriadas, globosas, desiguales, muricadas, negruzcas, de 1,6-2,0 mm de diámetro. Figura 4.

Distribución: en la región de las lomas de los departamentos de Arequipa, Moquegua y Tacna, entre los 0-1.000 metros de altitud.

Esta especie es muy afín a $N$. confinis Johnston de la que se diferencia principalmente por su aporte erguido, arboriforme, el indumento hirsuto-glanduloso; la corola más grande (hasta $22 \mathrm{~mm}$ de largo); las núculas 5-9, etc. 


\section{Nolana gracillima (Johnston) Johnston}

Sinonimia: Bargemontia gracillima I. M. Johnston

Planta anual, erguida, de $8-15 \mathrm{~cm}$ de alto; tallo subterete, grácil, ramoso, las ramas ascendentes, ligeramente pilosas, luego glabrescentes; hojas lineales, finamente pubescentes, luego glabrescentes, de 8-25 mm de largo por 0,8-1,5 mm de ancho, semisuculentas, pustulosas, glabrescentes, ápice obtuso, subsésiles; flores axilares, solitarias; pedicelo grácil, de 5-13 mm de largo, glabro o finamente piloso; cáliz de 4-6 mm de largo, esparcidamente velloso, luego glabrescente; tubo corto, cilíndrico, de 2,5-3,5 mm de largo, ascendentes; filamentos hasta $3,5 \mathrm{~mm}$ de longitud, adheridos a la corola; núculas 5 , uniseriadas ovoideas, negruzcas, de 1,5-2 $\mathrm{mm}$ de largo. Figura 5.

Distribución: es endémica de las vertientes occidentales de los Andes meridionales y de las lomas, entre los 700 y $2.000 \mathrm{~m}$ de altitud. También en el N.W. de Chile.

La presente entidad se acerca bastante a $N$. platyphylla Johnston, diferenciándose de ésta principalmente por su hábito glabrescente, las hojas lineales, glabrescentes y las núculas 5, negruzcas.

\section{Nolana jaffuelli Johnston}

Hierba anual, glabrescente, eglandulosa; tallo decumbente, de 10-30 cm de largo, simple o laxamente ramoso, fistuloso, las ramas de 2-3 $\mathrm{mm}$ de diámetro; hojas suculentas, oblanceoladas, adornadas por vesículas pequeñas, pecioladas, de $30-60 \mathrm{~mm}$ de largo, las hojas superiores sésiles, conspicuamente decurrentes y auriculadas, oblongolanceoladas o aovadas, de 6-12 $\mathrm{mm}$ de largo por 2-4 $\mathrm{mm}$ de ancho; pedicelo de 10-30 $\mathrm{mm}$ de longitud, ascendente, cáliz de 8-10 $\mathrm{mm}$ de largo, anguloso, el tubo de 5-6 mm de diámetro, los lóbulos trianguliformes, acuminados; corola infundibuliforme, violácea, de 13-20 mm de largo; estambres desiguales; núculas triseriadas, de 1-3 mm de diámetro, pálidas angulosas. Figura 6.

Distribución: habita en las lomas costaneras del norte de Chile, llega hasta las lomas de Tacna, entre los 700 y 900 metros de altitud.

Según el Dr. Ramón Ferreyra, se trata de una nueva especie chilena que avanza hasta las lomas del extremo sur de Perú.

\section{Nolana confinis (Johnston) Johnston}

Planta subfruticosa procumbente; raíz pivotante, simple o poco ramificada, hasta $32 \mathrm{~cm}$ de largo por 5-15 mm de diámetro; tallo hasta $4 \mathrm{~mm}$ de diámetro en la base, conspicuamente ramoso, las ramas usualmente procumbentes, ligeramente lanuginosas, luego glabrescentes; hojas lineales u oscuramente espatuladas, dispuestas en fascículos cortos, sésiles, semisuculentas, escasamente pubescentes o glabrescentes, de 6-15 $\mathrm{mm}$ de largo por 1,6-1,8 $\mathrm{mm}$ de ancho, obtusas, margen ligeramente revoluto, uninerviadas, algo encorvadas; pedicelo de 3-13 mm de longitud más o menos lanuginoso;

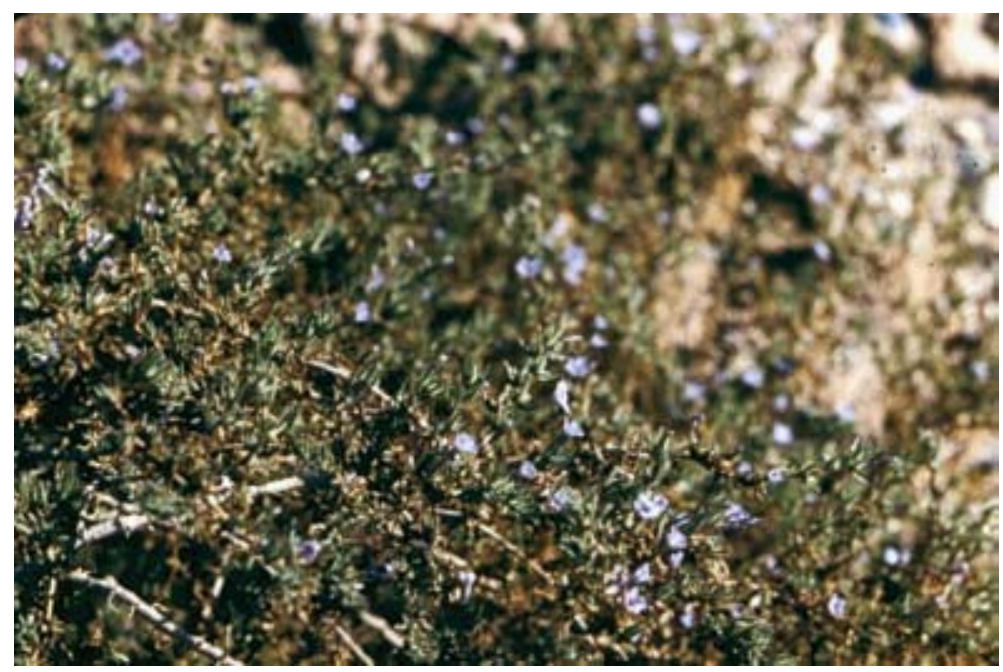

Figura 5. Nolana gracillima, pequeña, en la vegetación desértica del chaparral, Quilla, 1650 m.s.n.m. 


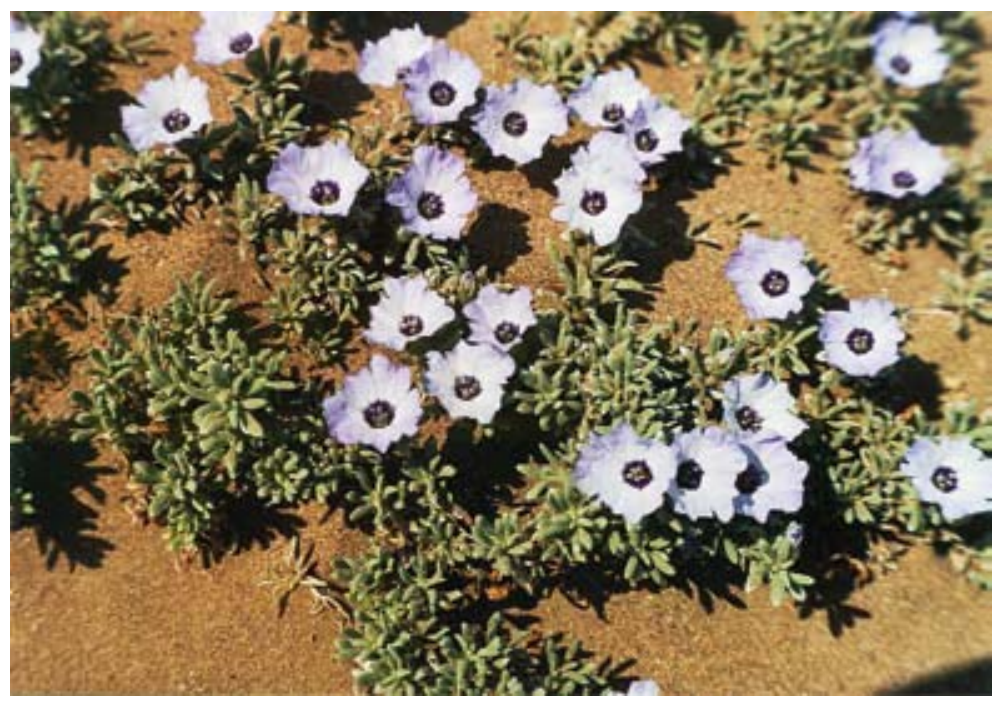

Figura 6. Nolana jaffuelli, pequeña, en la vegetación desértica del chaparral, Quilla, 1.650 m.s.n.m.

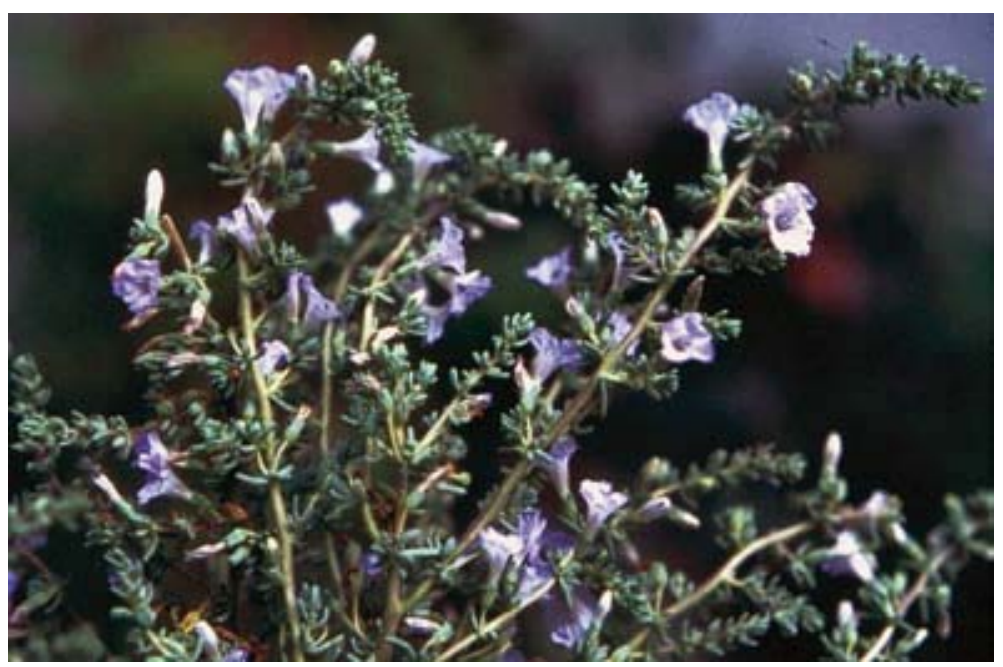

Figura 7. Nolana confinis, Nolanaceae, especie herbácea poco frecuente, pubescente, lomas de Sama-Locumba.

cáliz de 5,0-6,5 $\mathrm{mm}$ de largo por 2,4-3,0 $\mathrm{mm}$ de diámetro, acampanado; glanduloso-glabrescente afuera o largo adentro, el tubo corto hasta $3 \mathrm{~mm}$ de largo, los lóbulos 5, más o menos iguales de 2,8-5,0 $\mathrm{mm}$ de largo por 1-2 $\mathrm{mm}$ de ancho en su base, el margen transparente piloso, acuminados, ascendentes; corola infundibuliforme, azulada, de 10-15 mm de largo por 4,8-9,0 $\mathrm{mm}$ de ancho en su parte superior, 5-lobulada, los lóbulos desiguales eciliados, aovado-trianguliformes, obtusos, glabros, el tubo ligeramente piloso afue$\mathrm{ra}$, inconspicuamente velloso adentro; estambres desiguales, 3 mayores de 6,5-10 $\mathrm{mm}$ de largo, unidos al tubo $1 / 3$ de su longitud, 2 menores de 4,5-7 mm de largo unidos al tubo 1/3-1/4 de su longitud; estilo de $6,2-9,0 \mathrm{~mm}$ de longitud; núculas 3-4 raramente 5, desde globosas hasta reniformes, uniseriadas, desiguales las mayores de 3,5 $\mathrm{mm}$ de largo por 1,8-2,0 $\mathrm{mm}$ de ancho, las menores de 1,6-2,0 mm de largo por 1,2-1,5 mm de ancho, negruzcas, muricadas, más o menos brillantes. Figura 9 y Figura 7.

Distribución: es endémica del extremos sur peruano, entre los 500-400 metros de altitud. 


\section{Nolana arenicola Johnston}

Planta anual, de $20-40 \mathrm{~cm}$ de alto; raíz más o menos pivotante, de $12-16 \mathrm{~cm}$ de largo por 6-8 $\mathrm{mm}$ de diámetro; tallo erguido, de $5-8 \mathrm{~mm}$ de diámetro, glandulífero-pubescente, luego ligeramente glabrescente, ramoso, las ramas ascendentes de 7-18 $\mathrm{cm}$ de largo por 1,2-3 $\mathrm{mm}$ de diámetro, conspicuamente glanduloso-pubescentes; hojas numerosas, largamente pecioladas, suculentas, el limbo lanceolado-espatulado, de $18-45 \mathrm{~mm}$ de largo por 6-18 $\mathrm{mm}$ de ancho, de margen entero, el ápice agudo, glanduloso-pubescente; pecíolo de 7-16 $\mathrm{mm}$ de longitud, glanduloso-pubescente; pedicelo de 7-12 mm de longitud, densamente glandulosopubescente; cáliz de 11-15 mm de largo por 5,0$6,5 \mathrm{~mm}$ de diámetro, más o menos acampanado, densamente pubescente afuera, los pelos flexuosos, apretados, los lóbulos de 4,5-6,0 mm de largo por 1-2 mm de ancho, ligeramente espatulados, agudos; corola celeste, infundibuliforme, de $18-22 \mathrm{~mm}$ de largo por 17-19 mm de ancho, inconspicuamente lobulada, tubo corto; estambres desiguales, 2 mayores de 13-14 mm de largo, unidos al tubo casi $1 / 2$ de su longitud, 3 menores de 11-12 mm de largo, unidos al tubo 1/2 de su longitud; estilo de 7,5-9,5 mm de largo; núculas 5-10, uniseriadas, 5 mayores de 5-6 $\mathrm{mm}$ de largo por 4-5 $\mathrm{mm}$ de ancho, 3-5 menores de 2,8-3,5 mm de largo por 1,0-2,2 $\mathrm{mm}$ de ancho, negras muricadas brillantes; receptáculo de 5-7 mm de diámetro. Figura 8 y Figura 9.

Distribución: solamente en las lomas del extremos sur de Perú, entre los 500 y 1.000 metros de altitud.
Se relaciona mucho a $N$. spathulata, pero con respecto a ésta se diferencia por las hojas lanceolado-espatuladas, más angostas (hasta $18 \mathrm{~mm}$ de ancho); el ápice agudo; el pedicelo más corto (hasta $12 \mathrm{~mm}$ de longitud); las núculas 6-10.

\section{Nolana adansoni (Roemer \& Schultes) I. M. Johnston}

Sinonimia: Nolana cordata (Remy) Dunal, Sorema cordata

Planta subfruticosa, arboriforme, de 40-60 $\mathrm{cm}$ de alto; tallo erguido, glandulífero, ramoso, las ramas de 6-15 cm de largo por 1-2 $\mathrm{mm}$ de diámetro, glandulosas; hojas numerosas, largamente pecioladas, el limbo usualmente cordiforme, raras veces reniformes, de 5-12 $\mathrm{mm}$ de largo por 4-11 $\mathrm{mm}$ de ancho, de margen entero, el ápice obtuso, glanduloso, suculento; pecíolo de 4-8 mm de longitud, ligeramente pubescente-glanduloso, su base estipuliforme, conspicuamente amplexicaule; pedicelo de 1-3 mm de longitud, poco glanduloso; cáliz de 5-8 $\mathrm{mm}$ de largo por 5-6 $\mathrm{mm}$ de diámetro, glanduloso afuera pubescente adentro, los pelos erguidos, de 0,2-0,4 $\mathrm{mm}$ de largo, el tubo acampanado, de 3-5 mm de largo por 2,8-3,2 $\mathrm{mm}$ de diámetro, los lóbulos ascendentes, iguales, más o menos agudos, de 1,8-2,2 $\mathrm{mm}$ de largo por 1,2-1,8 $\mathrm{mm}$ de ancho; corola infundibuliforme, azulada, de $21-26 \mathrm{~mm}$ de largo por 5-7 $\mathrm{mm}$ de ancho en su parte superior, los lóbulos ascendentes, heteromorfos, 2 agudos, 3 obtusos; estambres desiguales, 2-mayores de 16-17 mm de largo, 3-menores de 13-14 mm de largo unidos al tubo la $1 / 2$ de su longitud; estilo de $14-15 \mathrm{~mm}$

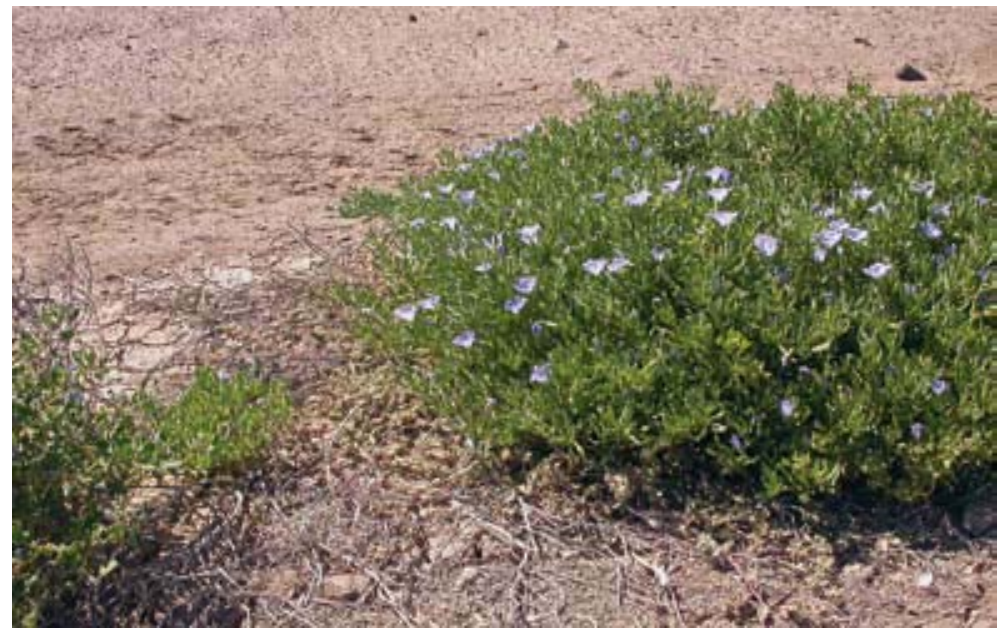

Figura 8. Densa Vegetación herbácea y efímera de Nolana arenicola, lomas de SamaLocumba. 


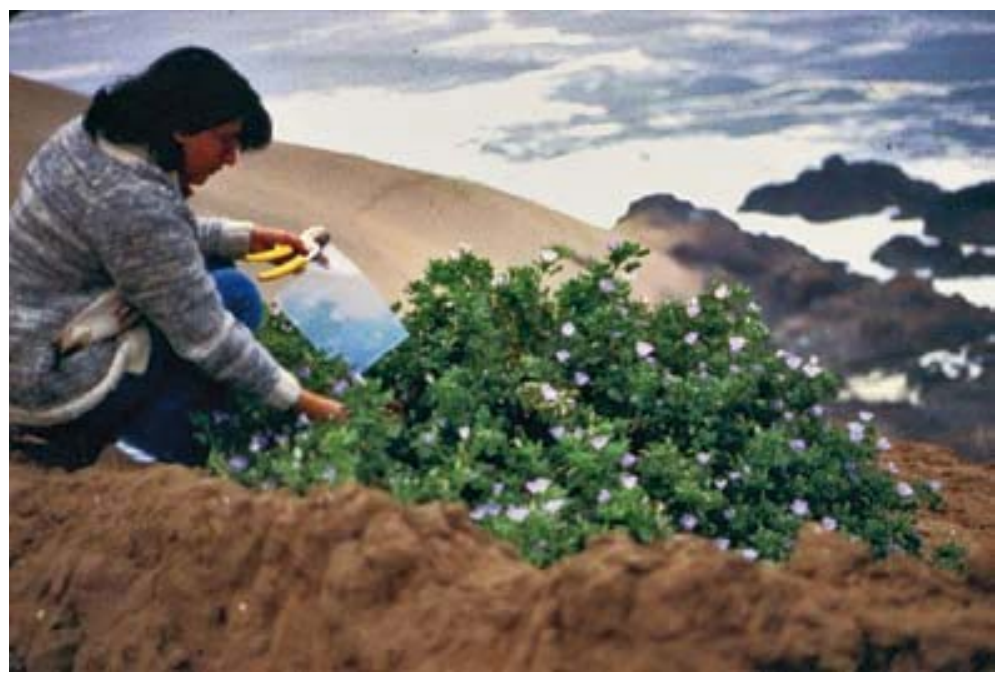

Figura 9. Nolana arenicola, Nolanaceae, colinas arenosas costeras cerca a Puerto Grau.

de longitud; núculas de 15-20, dispuestas en 3 series superpuestas, adheridas en un receptáculo ginobásico bien desarrollado, globosas, las superiores mayores, de 1,5-2,0 mm de diámetro las inferiores menores hasta $1 \mathrm{~mm}$ de diámetro, negruzcas; receptáculo de 3,5-4,0 mm de diámetro. Figura 10.

Distribución: habita en las playas marítimas del sur peruano, entre los 0-500 m.

Es una especie halófila frecuente en la costa meridional peruana que se caracteriza por sus hojas cordiformes o reniformes, sus pecíolos estipulíferos; su hábito conspicuamente glanduloso y brillante; sus núculas pequeñas y numerosas.

\section{Nolana Johnstonii Vargas}

Planta herbácea semisuculenta bianual, densa de $3-10 \mathrm{~mm}$ de diámetro, tallo de $20-30 \mathrm{~cm}$ de alto, ramoso, ramos decumbentes, glandulosopilosos, entrenudos de 15-22 mm de largo. Hojas semisuculentas aovado-espatuladas de 20-30 mm de largo, la base gradualmente alternada, el margen glanduloso-piloso. Pecíolo de 2-4 mm de longitud, pedicelo en 2-10 $\mathrm{mm}$ de largo. Cáliz tubuloso de 5-7 $\mathrm{mm}$ de largo por 3-4 $\mathrm{mm}$ de diámetro piloso glanduloso esparcidamente. Lóbulos del cáliz linear acuminados de 3-4 $\mathrm{mm}$ de largo. Corola muy vistosa infundibuliforme, azul-violácea de

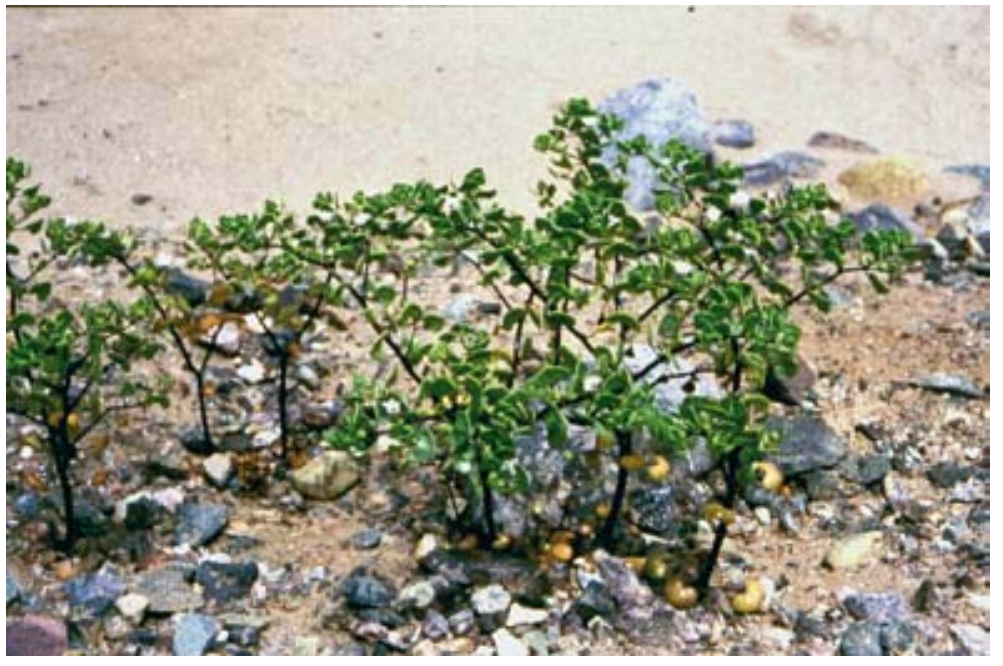

Figura 10. Especímenes de Nolana adansoni, Nolanácea, con tallos negruzcos, Morro Sama. 
10-15 mm de largo por 10-15 $\mathrm{mm}$ de diámetro en la parte superior, lobulados, lóbulos obtusos. Estambres dos iguales, dos mayores a 8-9 $\mathrm{mm}$ y tres menores de 6-7 mm de largo, unidos al tubo más o menos a la mitad de su longitud. Estilo de $9-10 \mathrm{~mm}$ de largo núculas (5-12) glisosas de 1,5-2,2 mm de diámetro, negruzcas, opacos. Figura 11.

Distribución: lomas de Sama-Locumba.

\section{Nolana plicata Johnston}

Planta subfruticosa muy ramificada y semisuculenta mayormente formando densas "colonias circulares" en las llanuras arenosas. Ramas decumbentes y postradas de $5-20 \mathrm{~cm}$ de longitud, estriadas y ligeramente pubescentes. Raíz pivotante suculenta, persistente poco ramificada o simple de 10-20 cm de longitud. Tallo procumbente, hojas numerosas, espatuladas o espatulidu-lanceoladas de 30-60 $\mathrm{mm}$ de longitud por 3-15 $\mathrm{mm}$ de ancho, de ápice obtuso, la base largamente atenuada, sésiles, semisuculentas y glandulosas. Cáliz de 10-17 mm de longitud, de 7-10 mm de diámetro, plegado al tubo ligeramente terete, glanduloso. Flores con corola azul-violáceo, infundibuliforme, de 15-35 $\mathrm{mm}$ de longitud por 7-30 $\mathrm{mm}$ de ancho en la parte superior, lobulada. Cinco estambres, 2 mayores de $15-16 \mathrm{~mm}$ de largo, 3 menores de 10-13 mm de largo. Estilo de 6-12 mm de longitud, Núculas 5, uniseriadas, reniformes de 3-5 mm de largo por 2-5 $\mathrm{mm}$ de ancho, opacos. Figura 12 y Figura 13.

Distribución: En las lomas y torrenteras del sur del Perú desde el nivel del mar hasta 500-600 m.s.n.m.

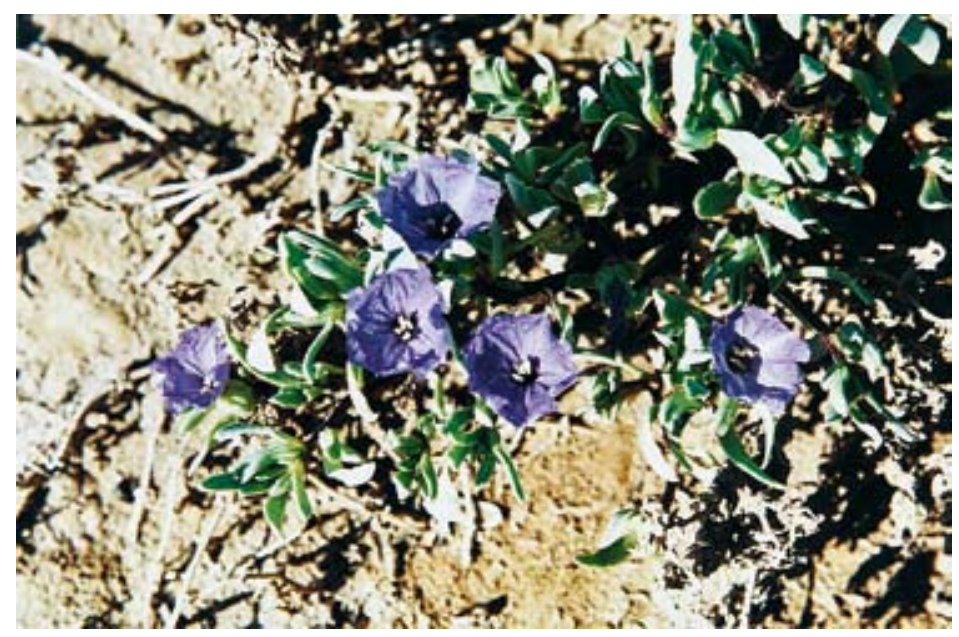

Figura 11. Nolana johnstonii, en las lomas de Sama-Locumba mostrando flores azul-violáceos muy vistosas.

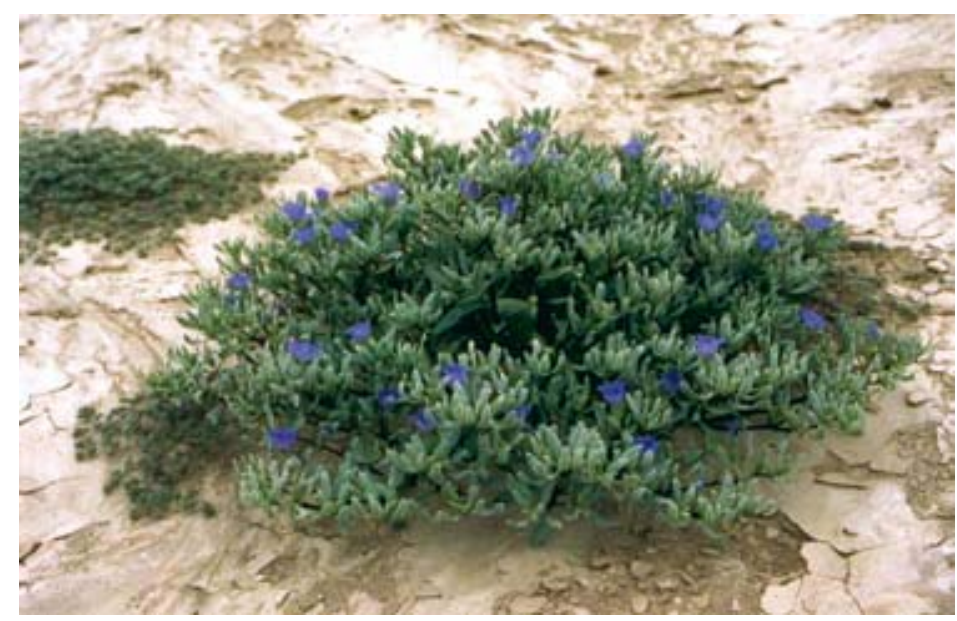

Figura 12. Nolana plicata, de flor azul-moradas, frecuente en las lomas de SamaLocumba. 


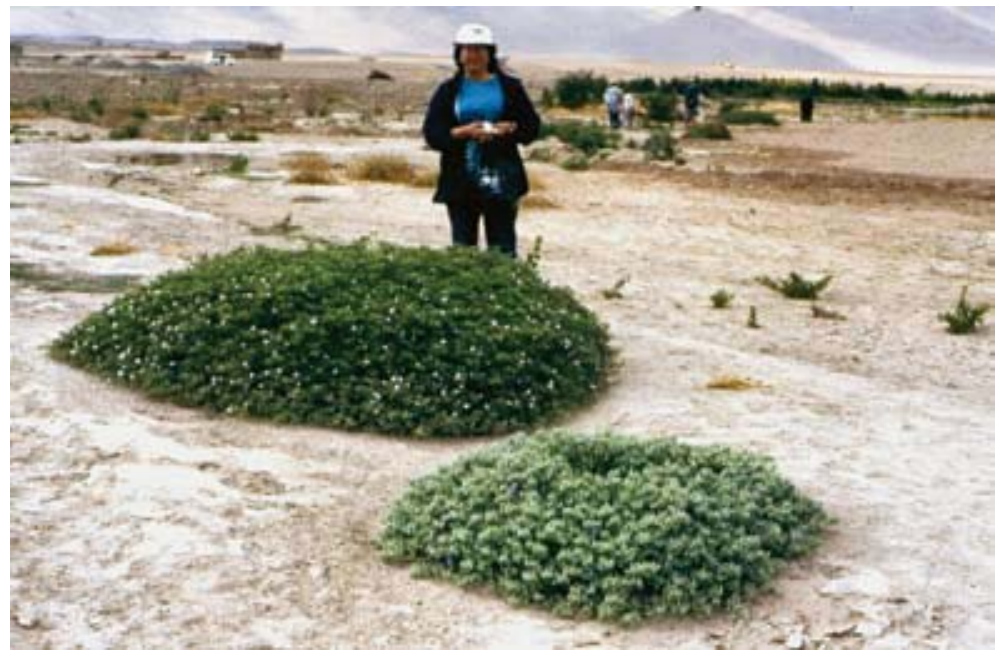

Figura 13. Biomasa aérea circular con plantas de Nolana plicata, en las torrenteras arenosas de Magollo, 400 m.s.n.m.

\section{LITERATURA CITADA}

BRAKO L.; J. L. ZARUCHI (1993). Catalogue of the flowering plants and Gymnosperms of Peru. Edit. Missouri Botanical Garden, USA, p. 1285.

CHÁVEZ, R. (2002). Mejoramiento Genético de Plantas Tuberíferas para zonas árido-salinas. Edit. Art Graphics, 220 p.

FERREYRA, R. (1953). "Las Comunidades Vegetales de algunas Lomas Costaneras de Perú". Est. Exp. Agrícola de La Molina, Bol. No 53. Lima.

FERREYRA, R. (1957). "Contribución al Conocimiento de la Flora Costanera del Norte Peruano (Departamento de Tumbes)”. Bol. de la Sociedad Argentina de Botánica.

FERREYRA, R. (1960). "Algunos Aspectos Fitogeográficos de Perú". Revista del Instituto Geográfico No 6 . U.N.M.S.M., Lima.

FERREYRA, R. (1961). "Las Lomas Costaneras del Extenso Sur de Perú". Revista de la Sociedad Argentina de Botánica, Buenos Aires.

FERREYRA, R. (1961). "Revisión de las Especies Peruanas del Género Nolana". Memorias del Museo de Historia Natural "Javier Prado", No 12, Lima.
JOHNSTON I.M. (1929). "Papers on the Flora of Northern Chile". Contr. Gray Herbarium-85: 1-138, U.S.A.

NAKAZAWA, M.; M. O. DILLON (1999). Biografía y Evaluación del Clado Nolana (Nolanaceae-Solanaceae). Arnaldoa 6(2). 81-116

PEFAUR, J.; E. LÓPEZ; J. DÁVILA (1981). "Ecología de la Biocenosis de las Lomas de Arequipa”. Boletín Lima, $\mathrm{N}^{\circ}$ 16-17-8: Dic. 1981.

PUPPO, P. (2005). Las Nolanas: Habitantes de las lomas. Rev. Quepo, Vol. 19-2005, pp 26-33.

RUNDEL, P.W.; M. O. DILLON; B. PALMA MOONEY; H.A. EHLERINGER (1991). "The phytogeofraphic and ecology of the coastal Atacama and Peruvian Deserts", Aliso 1991, pp. 1-49.

ZEGARRA, R. (2005). Biodiversidad y Taxonómia de la Flora Desértica sur Peruana: Familia Solanaceae. IDESIA 23-3, pp: 61-75. 